$1 \mathrm{mmHg}$. So sánh với tác giả khác như ta thấy kết quả tương đồng như Phạm Tân Tiến (2008) [6] nhãn áp trung bình sau mổ 1 tháng là 17,45 $\pm 1,49 \mathrm{mmHg}$.

4.3.3. Biến chứng sau phẫu thuật. Trong nghiên cứu của chúng tôi trên 16 mắt cắt bè củng giác mạc và 25 mắt cắt mống mắt chu biên thì trên cả 41 mắt đều chưa ghi nhận các biến chứng tại các thời điểm theo dõi.

Trong phẫu thuật cắt bè củng giác mạc, theo nghiên cứu của Nguyễn Hồ Việt Liên, Phan Văn Năm (2014) [7] thì tỷ lệ gặp biến chứng sau phẫu thuật như viêm màng bồ đào chiếm $12,5 \%$ và đục thể thửy tinh là 6,3\% sau 3 tháng theo dõi.

Trong phẫu thuật laser mống mắt chu biên theo tác giả Vũ Thị Thái, Nguyễn Thị Hà Thanh (2018) [8], nghiên cứu trên 141 mắt trong 2 năm thì cũng không có trường hợp nào bị bít hay không rõ lỗ cắt, ngoài ra cũng không gặp các biến chứng khác.

Có sự khác biệt giữa nghiên cứu của chúng tôi so với các tác giả khác là do số bệnh nhân nghiên cứu của chúng tôi là ít hơn rất nhiêu so với các nghiên cứu khác đồng thời thời gian theo dõi rất ngắn (1 tháng) nên không thể theo dõi được các biến chứng muộn sau phẫu thuật như viêm màng bồ đào hay đục thể thủy tinh.

\section{KẾT LUẦN}

1. Đặc điểm lâm sàng, cận lâm sàng

- Bệnh nhân chủ yếu trền 60 tuổi chiếm $73,4 \%$, tuổi trung bình $64,2 \pm 10,7$ tuổi. Nữ gấp đôi nam.

- Triệu chứng lâm sàng thường gặp: nhìn mờ (90\%) và đau nhức $(93,3 \%)$, tiền phòng nông
(100\%) , thị lực giảm, nhãn áp tăng

- Triệu chứng cận lâm sàng trên OCT: chủ yếu mức lõm đĩa $>0,3(83,8 \%)$.

\section{Kết quả điêu trị}

- Thị lực tăng ít hoặc ổn định

- Sau phẫu thuật nhãn áp trung bình còn

$17,4 \pm 1,1 \mathrm{mmHg}$.

- Không có biến chứng sau phẫu thuật.

\section{TÀl LIẸU THAM KHẢO}

1. Giangiacomo A, Coleman AL (2009). The epidemiology of Glaucoma.Glaucoma, Spinger, Hardcover, pp22-26.

2. Đố Như Hơn (2011). Đại cương Glôcôm, Nhãn khoa, Nhà xuất bản Y học, pp 224-235.

3. Pham Thi Thu Hà (2018). Nghiên cứu đăc điềm lâm sàng và kết quả điều trị Glôcôm ác tính, Luận văn tiến sĩ y học, Trường đai hoc Y Hà Nội.

4. Zhonghua Yan Ke Za Zhi (2019). Preliminary efficacy of penetrating canaloplasty in primary angle- closure Glaucoma. The eyes hospital of Wenzhou Medical.

5. Lương Thi Hải Hà, Đăng Đức Minh (2019). Đăc điểm rối loạn sắc giác trên bệnh nhân Glôcôm nguyên phát. Tap chí Y dược lâm sàng 108, trường đại học y dược Thái Nguyên.

6. Phạm Tân Tiến (2008). Nghiên cứu ứng dụng laser Nd:YAG với hai bước sóng khác nhau cắt mống mắt chu biên điêu trị Glôcôm góc đóng, Luận văn tiến sỹ y học, Học viện Quân y.

7. Nguyến Hồ Việt Liên, Phan Văn Năm (2014). Nghiên cứu đăc điểm lâm sàng và kết guả điều trị Glôcôm góc đóng nguyên phát bằng phâuu thuật tai Khoa Mắt Bệnh viện Trung ương Huê. luận văn bác sĩ nôi trú, trường Đ̇ai hoc $Y$ dước Huế

8. Vũ Thị Thái, Nguyến Thị Hà Thanh (2018). Đánh giá kết quả lâu dài của phẫu thuật cắt mống mắt chu biên điêu trị Glôcôm nguyên phát tại khoa Glôcôm bệnh viện Mắt Trung ương, luận vằn tiến sĩ, trường Đại học y Hà Nội.

\title{
ĐÁNH GIÁ KẾT QUẢ THẨM MỸ 5 NĂM XA TRI ĐIỀU BIẾN LIỀU SAU PHẪU THUÂTT UNG THƯ VÚ BẢO TỒN GIAI ĐOẠN I-II TẠI BÊ̂NH VIỆN K
}

\section{TÓM TẮT}

Ung thư vú là bênh ung thư thường găp nhất ở phụ nữ. Điều trị bảo tồn chỉ định cho giai đoạn I-II, xạ trị bổ trợ sau phẫu thuật bảo tồn là chỉ định bắt buộc.

*Bệnh viện $K$

Chịu trách nhiệm chính: Nguyễn Công Hoàng

Email: hoangdoc@gmail.com

Ngày nhận bài: 9.8.2021

Ngày phản biên khoa hoc: 4.10 .2021

Ngày duyệt bài: 14.10 .2021

\section{Nguyễn Công Hoàng ${ }^{1}$, Đinh Công Định ${ }^{2}$}

Xạ trị điều biến liều (F-IMRT) là kỹ thuật sử dụng máy gia tốc có trang bi hê thống collimator đa lá có khả năng tối ưu hóa kế hoạch xạ trị, cải thiện rõ rệt phân bố liều tai thể tích điều trị, giảm liều xa vào tổ chức lành xung quanh. Nghiên cứu nhằm nhẩn xét một số đăc điểm lâm sàng và đánh giá kết quá̉ thẩm mỹ̃ tai thời điểm 5 năm sau xạ trị điêu biến liều ung thư vú bảo tồn tại bệnh viện $K$. Đối tượng và phương pháp nghiên cứu: 68 bệnh nhân đủ tiêu chuẩn cụ thể giai đoạn I, II điều trị bảo tồn tại Bệnh viện $\mathrm{K}$ từ tháng 02/2016 đến 10/2021. Xa trị kỹ thuật điểu biến liều (F-IMRT). Nghiên cứu mô tả, tiến hành thu thập 
thông tin về lâm sàng, đánh giá kết quả điều trị sau 5 năm, kết quả thẩm mỹ theo thang điểm Lowery Carlson. Kết quả: Trung vị tuổi BN là 44, trẻ nhất 21, vị trí u $1 / 4$ trên ngoài thường gặp nhất $(64,2 \%)$, giai đoạn I -IIA 91,2\% là chủ yếu. Thể tích vú trung bình và nhỏ chiếm đa số $90,3 \%$. Thời gian sống thêm không bệnh 5 năm là 92,6\%, sống thêm toàn bộ 5 năm là $95,6 \%$. Kết quả thẩm mỹ mức đạt chiếm 80,2\%. Kết luận: Trong nghiên cứu tuổi trung bình khá trẻ, hiệu quả điều trị bệnh tốt, kết quả thẩm mỹ mức đạt khá cao. Tuy nhiên các biến chứng của xạ trị ảnh hưởng đến kết quả thẩm mỹ thường muộn sau khi điều trị nhiều năm, vây cần có theo dõi dài hơn sau điều trị để có những kết luận chính xác hơn.

\section{SUMMARY}

\section{YEARS COSMETIC OUTCOME AFTER} INTENSITY MODULATED RADIATION THERAPY FOLLOWED CONSERVATIVE SURGERY OF BREAST CANCER STAGE I-II AT K HOSPITAL

Breast cancer is the most common cancer in women. While conservative treatment is indicated for early stage breast cancer (stage I-II), adjuvant radiation therapy is mandatory. Forward intensity modulated radiotherapy (F-IMRT) is a modern radiation technique by using LINAC with multileaf collimator system to optimize radiation treatment plan in order to improve homogeneity of PTV, minimizing the dose to organ at risks. Our study aims to review clinical features and 5 years cosmetic outcome after FIMRT followed breast cancer conservative treatment of at $K$ hospital. Objectives and methods: 68 eligible patients with stage I-II breast cancer were selected, treated by forward IMRT followed conservative surgery from 2/2016 to 10/2021 at K Hospital. Review clinical features and estimate cosmetic outcome at the end of 5 years postoperative radiotherapy. Result: Clinical features of 68 eligible patients: median age is 44; the lowest is 21; tumor location: left breast accounted for $61.2 \%$, upper outer quadrant of the breast is most common (64.2\%). TNM stage: mostly stage I-IIA (91.2\%); Breat volume: most patients with small and average breast volume (90.3\%). The 5-year disease-free survival (DFS) rates are $92.6 \%$. The 5years overall survival (OS) rates is $95.6 \%$. Quality of cosmetic outcome account for $80.2 \%$ (Excellent: $37.6 \%$; Good: $20.8 \%$; Fair: $21.8 \%$ ). Conclusion: In our study, the 5-year disease-free survival was $92.6 \%$, the 5 -year overall survival was $95.6 \%$. we found that high rate of fair, good and excellent cosmetic result group reached $80.2 \%$. The side effects of radiation therapy that affect cosmetic results often occur late, so long-term follow-up after treatment is required for more accurate conclusions.

\section{I. ĐĂT VẤN ĐỀ}

Ung thư vú là bênh hay găp nhất ở phụ nữ và là nguyên nhân gây tử vong thứ hai sau ung thư phổi tại các nước trên thế giới. Theo Globocan 2018, tại Việt Nam hàng năm có khoảng 15229 ca mới mắc, số tử vong là hơn 6000 bệnh nhân. Theo nghiên cứu gánh nặng bệnh ung thư và chiến lược phòng chống ung thư quốc gia đến năm 2020 thì UTV là bệnh có tỷ lệ mới mắc cao nhất trong các ung thư ở nữ giới [1].

Nguyên tắc chung của điều trị ung thư vú là điều trị phối hợp các phương pháp phẫu thuật, xạ trị và điều trị toàn thân. Kỹ thuật xạ 3D vẫn là phổ biến nhất, tỷ lệ tái phát tại chỗ sau 05 năm từ $4,5 \%-12 \%$. Tuy nhiên các tác dụng phu muộn như xơ hóa diên chiếu xạ, phù bạch huyết tay, teo tuyến vú... vẫn thường hay gặp gây biến dang, thay đổi sắc tố da, mô vú teo nhỏ mất cân đối, mật độ cứng, ảnh hưởng nhiều đến thẩm mỹ [2], [3]. Xa trị điều biến liều (F-IMRT) là kỹ thuật sử dụng máy gia tốc có trang bị hệ thống collimator đa lá, các trường chiếu nhỏ được tạo ra nhằm tối ưu hóa kế hoạch xạ trị, cải thiện về phân bố liều xạ, tăng khả năng tập trung liểu tại thể tích điều trị, hạn chế liều tới tổ chức lành xung quanh. Kết quả điều trị bệnh và thẩm mỹ cải thiện có ý nghĩa thống kề, biến chứng da bị xơ chai cứng, mô vú teo nhỏ với thể tích vú còn $<50 \%$ không gặp ở nhóm điều trị F-IMRT [3]. Bênh viện $\mathrm{K}$ áp dụng kỹ thuật xạ trị này trong điều trị UTV bảo tồn hơn 5 năm, chúng tôi tiến hành đề tài với muc tiêu:

Một số đặc điểm lâm sàng nhóm nghiên cứu

Đánh giá kết quả thẩm mỹ 5 năm sau xạ trị điều biến liều ung thư vú bảo tồn

\section{II. ĐỐI TƯỢNG VÀ PHƯƠNG PHÁP NGHIÊN CỨU}

Đối tượng nghiên cứu. 68 bệnh nhân đủ tiêu chuẩn được lựa chọn vào nghiên cứu với các tiêu chí cư thể: ung thư vú nữ, một bên được điều trị bảo tồn, giai đoạn sớm (T1-2 N0-1 MO) theo AJCC 2010, tuân thủ đầy đủ phác đồ, có chì số toàn trạng (PS) 0-1. Không lựa chọn BN có tiền sử ung thư khác, đã xạ vào vùng ngực, vú. Thời gian từ tháng 02/2016 đến 10/2021, tại Bệnh viện K.

Phương pháp nghiên cứu mô tả chùm ca bệnh

Các bước tiến hành: Thu thập thông tin về đặc điểm bệnh nhân, phương pháp điều trị.

Xa trị: Phương tiện máy CT mô phỏng, máy gia tốc với collimator đa lá mức năng lượng 6 MV, dụng cụ cố định, kỹ thuật xạ trị điều biến liều (F-IMRT) liều toàn vú 50Gy, liều tăng cường tại vị trí u 14-16Gy.

Mô phỏng điều trị, lâp kế hoạch điều trị theo ICRU 50 và 62 , đánh giá chất lượng trước xạ trị, tiến hành xạ trị và đánh giá kết quả.

Tiêu chuẩn đánh giá: Phân loại giai đoạn theo AJCC - 2010, đánh giá kết quả điều trị, đánh giá thẩm mỹ theo thang điểm Lowery Carlson. 


\section{KẾT QUẢ NGHIÊN CỨU VÀ BÀN LUẬN Bảng 1. Môt số đặc điểm lâm sàng}

\begin{tabular}{|c|c|c|c|}
\hline Đặc điểm & 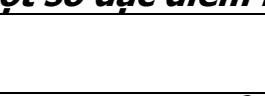 & n: 68 & $\begin{array}{l}\text { Tỷ lệ } \\
(\%)\end{array}$ \\
\hline \multirow{3}{*}{$\begin{array}{l}\text { Thể tích vú } \\
\text { (V) }\end{array}$} & V-To: $>975 \mathrm{~cm}^{3}$ & 10 & 9,7 \\
\hline & $\begin{array}{c}\text { V - TB: } 500- \\
975 \mathrm{~cm}^{3}\end{array}$ & 64 & 62,1 \\
\hline & $\begin{array}{c}\text { V - Nhỏ: } \leq 500 \\
\mathrm{~cm}^{3}\end{array}$ & 29 & 28,2 \\
\hline \multirow{3}{*}{$\begin{array}{l}\text { Giai đoạn } \\
\text { (TNM) }\end{array}$} & I & 42 & 61,8 \\
\hline & IIA & 20 & 29,4 \\
\hline & IIB & 6 & 8,8 \\
\hline \multirow{2}{*}{$\begin{array}{l}\text { Phẩu thuâat } \\
\text { Bảo tôn vú + } \\
\text { tạo hình }\end{array}$} & Có & 31 & 45,6 \\
\hline & Không & 37 & 54,4 \\
\hline \multirow{2}{*}{$\begin{array}{l}\text { Điều trị hóa } \\
\text { chất }\end{array}$} & Có & 39 & 57,4 \\
\hline & Không & 29 & 42,8 \\
\hline \multirow{2}{*}{$\begin{array}{c}\text { Điều trị nội } \\
\text { tiết }\end{array}$} & Có & 42 & 61,8 \\
\hline & Không & 26 & 38,2 \\
\hline \multirow{6}{*}{ Vị trí u } & Vú trái & 37 & 54,4 \\
\hline & Vú phải & 31 & 43,6 \\
\hline & 1/4 trên-ngoài & 38 & 55,9 \\
\hline & 1/4 trên-trong & 9 & 13,2 \\
\hline & 1/4 dưới-ngoài & 14 & 20,6 \\
\hline & 1/4 dưới-trong & 7 & 10,3 \\
\hline
\end{tabular}

Trong nghiên cứu tuổi của bệnh nhân trung bình là 44, hay gặp nhất 40 đến 49 tuổi chiếm $38,8 \%$, trẻ hơn so với các nghiên cứu khác như tác giả Pham Hồng Khoa tuổi trung bình 50,5. U vú trái chiếm $54,4 \%$; $1 / 4$ trên ngoài hay gặp nhất (55,9\%). Theo Phạm Hồng Khoa (2016) thư vú trái là $56,8 \% ; 1 / 4$ trên ngoài là $64,2 \%$ [4]. Giai đoạn TNM phần lớn bệnh nhân là giai đoạn I IIA 91,2\%; giai đoạn IIB chỉ chiếm 8,8\%. Về thể tích vú: đa số bệnh nhân trong nhóm nghiên cứu có thể tích vú trung bình $\left(500-975 \mathrm{~cm}^{3}\right)$ chiếm $62,1 \%$; thể tích vú nhỏ $28,2 \%$, lớn chỉ chiếm $9,7 \%$. So với các tác giả ở phương Tây, Nhật Bản thấy rằng thể tích vú của phụ nữ tham gia nghiên cứu này nhỏ hơn, một nghiên cứu của

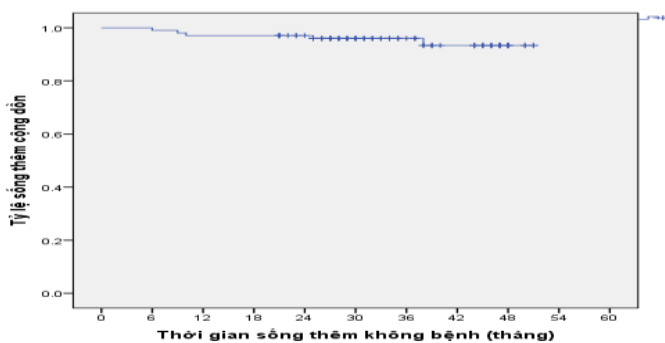

Biêu đồ 1. Thời gian sống thêm không bệnh, sông thêm toàn bộ

Thời gian sống thêm không bệnh (DFS) tại thời điểm 5 năm 92,6\%. Kết quả nghiên cứu này tương tự kết quả nghiên cứu của các tác giả
Philippe Piggnol (canada) cho thây kích thước vú $>975 \mathrm{~cm}^{3}$ chiếm 32,9\%, TB 50\%, kích thước nhỏ $<500 \mathrm{~cm}^{3}$ chỉ chiếm 17,1\%; tác giả Yuki Nohara (Japan) thì thấy răng kích thước vú $>975 \mathrm{~cm}^{3}$ chiếm $24,2 \%$, TB 58,6\%, kích thước nhỏ $<500$ $\mathrm{cm}^{3}$ chỉ chiếm $16,7 \%$ [5]. Về phương pháp điều trị thì có $57,4 \%$ bênh nhân được bổ trớ hóa chất trước khi xa trị và $42,8 \%$ được xa trị bổ trơ ngay sau phẫu thuật. Điều trị nội tiết có $61,8 \%$ bệnh nhân đó là những trường hợp $E R$ và/ hoặc $P R$ dương tính, tỷ lệ dương tính của thụ thể nội tiết cũng tương tự các nghiên cứu khác. Tác giả Ta Văn Tờ nghiên cứu trên 2207 bệnh nhân ung thư vú thây rẳng tỷ lệ $E R$ và/hoặc $P R$ dương tính là $63,3 \%$, trong đó $E R$ dương tính là $59,1 \%$, $P R$ dương tính là $51,4 \%$, tỷ lệ cả $E R$ và $P R$ dương tính là 47,2\% [6].

Thời gian sống thêm. Tính đến tháng 9 năm 2021, có 3 bênh nhân tử vong tai thời điểm 15 tháng và 48 tháng. Tỷ lê sống thềm toàn bộ (OS) 5 năm là $95,6 \%$. Trong số tử vong có bệnh nhân nữ 52 tuổi, ung thư vú giai đoạn T2NOMO, giải phẫu bệnh là ung thư thể tiểu thùy xâm nhâp, thu thể nôi tiết âm tính, Ki67 dương tính, HER 2 âm tính. Bệnh nhân được phẫu thuật bảo tồn kết hợp hóa chất bổ trợ phác đồ $4 A C-4 T$, tia xạ bổ trợ. Sau 25 tháng, xuất hiện tái phát di căn gan, bềnh nhân chuyển sang điều trị tai Hàn Quốc bệnh tiến triển và tử vong sau 48 tháng. Bệnh nhân khác nữ 45 tuổi, ung thư vú trái T2N1M0, ung thư thể ống xâm nhập độ III, thụ thể nội tiết âm tính Ki67 dương tính 100\%, HER 2 âm tính, sau phẩu thuật bảo tồn, chất bổ trợ phác đồ $4 A C-4 T$, tia xạ bổ trợ. Bệnh nhân tái phát di căn phổi sau xạ trị 10 tháng chuyển điêu trị hóa chất triêu chứng và tử vong sau xa trị 15 tháng. Kết quả nghiên cứu của chúng tôi phù hợp với các nghiên cứu của các tác giả khác như nghiên cứu Milan III cho kết quả sống thêm toàn bộ sau 5 năm 92\% [7].

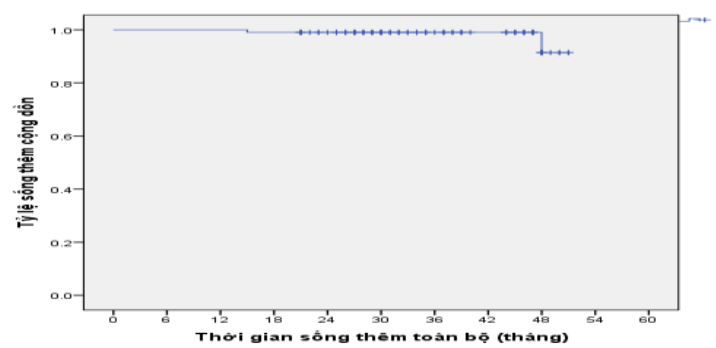

khác. Theo Hoàng Thanh Quang trên 64 bệnh nhân UTV giai đoạn I, II điều trị bảo tồn kết hợp xạ trị bổ trợ, tỷ lệ sống thêm không bệnh 5 năm 
là 85,5\%. Nghiên cứu của Ta Xuân Sơn tỷ lệ sống thêm không bệnh tại 4 năm là 92,5\% [8][9]

Trong nghiên cứu có 1 bệnh nhân tái phát tại chỗ tại thời điểm 38 tháng, 3 bệnh nhân tái phát di căn xương, 1 bệnh nhân tái phát di căn gan. Một trường hợp tái phát tại chỗ là bệnh nhân trẻ 30 tuổi, chẩn đoán $K$ vú (P) T1NOM0 được điều trị bảo tồn kết hợp xạ trị bổ trợ. Giải phẫu bệnh là thể tủy, thụ thể nội tiết âm tính, Her2/neu, âm tính, Ki67 dương tính 80\%. Bệnh nhân được điều trị hóa chất toàn thân $4 F A C-4 \mathrm{~T}$.

Kết quả thẩm mỹ vú bảo tôn sau xạ trị. Mục tiêu của điều trị ung thư vú là đạt kết quả kiểm soát ung thư tối ưu, bên cạnh đó kết quả thẩm mỹ rất được quan tâm vì nó ảnh hưởng rất lớn đến tâm lý, chất lượng sống của người bệnh. Theo kết quả nghiên cứu của các tác giả từ năm 1969 đến năm 1996, khoảng 70-87\% bệnh nhân có kết quả thẩm mỹ đạt mức đẹp hoặc tốt [10]. Các yếu tố phẫu thuật ảnh hưởng đến thẩm mỹ bao gồm thể tích cắt bỏ, sẹo mổ, cũng như diện tích da bị cắt bỏ $>20 \mathrm{~cm}^{2}$ [137]. Xạ trị ảnh hưởng đến thẩm mỹ bao gồm thể tích xạ trị, liều xạ vú và giường u, cũng như sự phân bố liều xạ tại thể tích điều trị.

Tại thời điểm 60 tháng chúng tôi thấy kết quả thẩm mỹ đẹp chiếm $37,6 \%$, tốt chiếm $20,8 \%$, trung bình chiếm $21,8 \%$, kém chiếm $19,8 \%$; có 1 bệnh nhân tử vong và 1 bệnh nhân tái phát tại chố trước thời điểm đánh giá. Theo kết quả của một số nghiên cứu, trên 30\% bệnh nhân không hài lòng về hình thể tuyến vú sau phẫu thuật bảo tồn. Nguyên nhân chính được đưa ra bao gồm: thiếu hụt mô tuyến, co kéo da gây biến dạng vú, co kéo/thay đổi vị trí phức hợp quầng-núm vú, mất cân đối hai vú và các tác dụng muộn của xạ trị tới bên vú phẫu thuật.

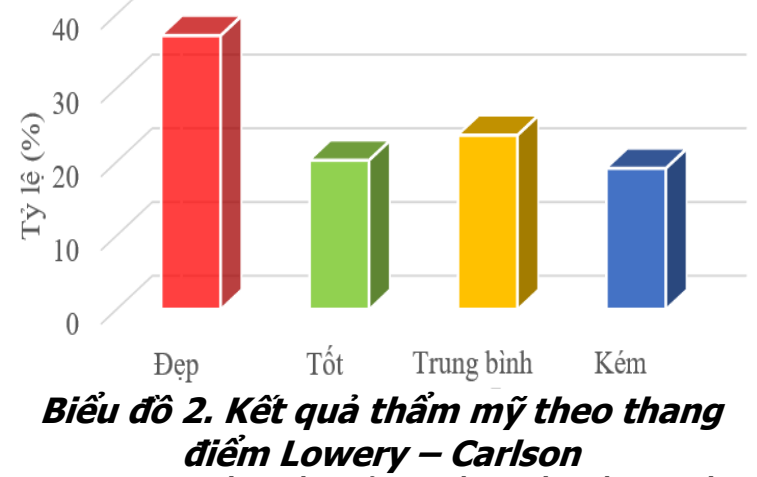

Trong nghiên cứu của chúng tôi có 34 bệnh nhân (33\%) được phẫu thuật bảo tồn kèm tạo hình tuyến vú. Khi phân tích yếu tố liên quan giữa kết quả thẩm mỹ và phương pháp phẫu thuật, chúng tôi chưa tìm thấy sự khác biệt có ý nghĩa thống kê giữa hai nhóm bệnh nhân có hoặc không kèm theo phẫu thuật tạo hình. Một lý do có thể giải thích là hầu hết các trường hợp bệnh nhân được phẫu thuật thuật tạo hình trong nghiên cứu của chúng tôi là do kích thước u lớn, gần vị trị trung tâm và các phương pháp tạo hình chủ yếu là dịch chuyển mô vú. Một lý do khác là do số lượng bệnh nhân giữa hai nhóm còn thấp và chưa cân xứng nhau.

Bảng 2. Phân tích đa biến các yếu tố liên quan kêt quả thẩm mỹ

\begin{tabular}{|c|c|c|}
\hline Yếu tố & B & $\mathbf{p}$ \\
\hline Tuối ( $\leq 50$ sv > 50 tuối) & $-0,170$ & 0,745 \\
\hline $\begin{array}{c}\text { Thế tích vú }(\leq 500 \mathrm{cc} \text { sv }>500 \\
\mathrm{cc})\end{array}$ & 0,145 & 0,790 \\
\hline Kích thước u $(\leq 2 \mathrm{~cm} \mathrm{sv}>2 \mathrm{~cm})$ & 0,122 & 0,831 \\
\hline Vị trí u (trong sv ngoài) & 0,014 & 0,978 \\
\hline $\begin{array}{l}\text { Phương pháp phâu thuất } \\
\text { (không sv có tạo hình) }\end{array}$ & $-0,643$ & 0,216 \\
\hline
\end{tabular}

Tác giả Taylor $\mathrm{ME}$ và Mills $\mathrm{JM}$ cho rằng khi thể tích mô vú bị cắt bỏ (bao gồm cả u) lớn hơn $100 \mathrm{~cm}^{2}$ có nguy cơ dẫn tới kết quả thẩm mỹ kém sau phẫu thuật nếu chỉ cắt rộng $\mathrm{u}$ đơn thuần. Tương ứng với tỷ lệ thể tích tuyến vú (bao gồm cả u) bị cắt bỏ trên $10 \%$ sẽ dẫn tới kết quả thẩm mỹ kém. Các tác giả đều cho rằng tỷ lệ kích thước u-kích thước tuyến vú có giá trị hơn kích thước $u$ đơn thuần trong tiên lượng kết quả thẩm mỹ sau phẫu thuật. Với các bệnh nhân phải tiến hành cắt lại do diện cắt dương tính, tỉ lệ kết quả thẩm mỹ thấp hơn các bệnh nhân không phải cắt lại. Vị trí u cũng ảnh hưởng tới kết quả thẩm mỹ, các khối u ở 1/2 dưới hoặc trung tâm tuyến vú cho kết quả thẩm mỹ kém hơn các khối u ở vị trí còn lại. Với các khối u nằm ở $1 / 2$ trong, do sự phân bố ít của mô tuyến ở khu vực này, thể tích tuyến vú cho phép cắt bỏ trong phẫu thuật là không quá $5 \%$ để đảm bảo kết quả thẩm mỹ sau phẩu thuât. Hình dang tuyến vú trước điều trị cũng ảnh hưởng tới kết quả thẩm mỹ. ở phụ nữ lớn tuổi, mô tuyến vú được thay thế bằng mô xơ-mõ̃, tổ chức da và mô nâng đõ tuyến vú cũng thay đổi, dẫn tới thay đổi về hình thể tuyến vú. Tác giả Taylor $\mathrm{ME}$ và $\mathrm{CS}$ cho rằng kết quả thẩm mỹ của nhóm bệnh nhân trên 60 tuổi kém hơn so với nhóm bệnh nhân trẻ hơn.

Các tác giả Kaur N và CS (2005), Schrenk $P$ và CS (2006), Giacalone PL và CS (2007) tiến hành nghiên cứu so sánh giữa hai nhóm bệnh nhân được phấu thuât bảo tồn kết hợp tạo hình và phẫu thuật bảo tồn đơn thuần cho thấy kích thước $u$ được bảo tồn lớn hơn, thể tích mô vú cắt được lớn hơn, tỷ lệ diện cắt âm tính và độ 
dầy diện cắt âm tính lớn hơn. Trong nhóm này, tỷ lệ phải phẫu thuật cắt thêm cũng thấp hơn. Kết quả thẩm mỹ của nhóm kết hợp tạo hình tốt hơn nhóm cắt rộng u đơn thuần.

\section{KẾT LUẬN}

Trong nghiên cứu, độ tuổi bệnh nhân khá trẻ, trẻ nhất 21 , vị trí u $1 / 4$ trên ngoài thường gặp nhất, giai đoạn I -IIA là chủ yếu. Thể tích vú trung bình và nhỏ chiếm đa số $90,3 \%$. Thời gian sống thêm không bệnh 5 năm là $92,6 \%$, sống thêm toàn bộ 5 năm là $95,6 \%$. Kết quả thẩm mỹ mức đạt chiểm 80,2\%. Các biến chứng của xạ trị ảnh hưởng đến kết quả thẩm mỹ thường xảy ra muộn vậy cần có theo dõi dài sau điều trị để có những kết luận chính xác hơn

\section{TÀI LIÊU THAM KHẢO}

1. GLOBOCAN (2018). Incidence, Mortality and Prevalence by cancer site, <https://gco.iarc.fr/today/ data/factsheets/cancers/ 20-Breast-fact-

2. Harsolia A, Kestin L, Grills I, Wallace M, Jolly $\mathbf{S}$, Jones $\mathbf{C}_{\text {, }}$ et al. "Intensity-modulated radiotherapy 2 . results in significant decrease in clinical toxicities compared with conventional wedge-based breast radiotherapy"'". Int J Radiat Oncol Biol Phys. 2007;68(5):1375-80.

4. Losken, C. S. Dugal, T. M. Styblo et al. (2014). A meta-analysis comparing breast conservation therapy alone to the oncoplastic technique. Ann Plast Surg, 72(2), 145 - 152

5. Pham Hồng Khoa (2016). Ung dụng phương pháp sinh thiết hạch cửa trong điều trị ung thư biểu mô tuyến vú giai đoạn sớm, Luận án Tiến sỹ Y học, Trường Đại học Y Hià Nội.

6. J. P. Pignol, I. Olivotto, E. Rakovitch et al. (2008). A multicenter randomized trial of breast intensity-modulated radiation therapy to reduce acute radiation dermatitis. J Clin Oncol, 26(13), 2085-92.

7. Tạ Văn Tờ (2004). Nghiên cứu hình thái học, hóa mô miễn dịch và giá trị tiên lượng của chúng trong ung thư biểu mô tuyến vú, Luận án Tiến sỹ Y học, Trường Đại học Y Hà Nội.

8. U. Veronesi, A. Luini, M. Del Vecchio et al. (1993). Radiotherapy after breast-preserving surgery in women with localized cancer of the breast. N Engl J Med, 328(22), 1587-91.

9. Hoàng Thanh Quang (2011). Đánh giá kết quả điều trị bảo tồn ung thư vú nữ giai đoạn I-II từ năm 2003-2006 tại Bệnh viện K, Luận văn Thạc sỹ Y học, Trường Đại học Y Hà Nội.

\section{ĐÁNH GIÁ KẾT QUẢ HÓA TRỊ BỔ TRỢ PHÁC ĐỒ 4AC-4D TRÊN BỆNH NHÂN UTV GIAI ĐOẠN II -IIIA BỆNH VIỆN UNG BƯỚU THANH HÓA}

\section{TÓM TẮT}

Mưc tiêu: Đánh giá kết quả sống thêm và một số yễu tổ liên quan trên bệnh nhân ung thư vú giai đoạn II-IIIA điều trị phác đồ hóa chất bổ trợ $4 \mathrm{AC}-4 \mathrm{D}$ (A: doxorubicine, $\mathrm{C}$; cyclophosphamide và $\mathrm{D}$ : docetaxel) áp dụng tại Bệnh viện Ung bướu Thanh Hóa. Đối tượng và phương pháp nghiên cứu: Bao gồm 74 bệnh nhân được chẩn đoán ung thư vú giai đoạn IIIIIA đã phẫu thuật triêtt căn, điêu trị hóa chất bổ trợ tại bệnh viện ung bướu Thanh Hóa, từ tháng 2 năm 2014 đến tháng 4 năm 2021. Kết quả: Tuổi trung bình của nhóm nghiên cứu là 46,62 $\pm 7,05$ tuổi.Tất cả 74 bệnh nhân đều hoàn thành 8 chu kỳ hóa chất $4 A C-$ $4 \mathrm{D}$, không có bệnh nhân nào dừng điêu trị. Thời gian nghiên cứu trung bình là 69 tháng, tỷ lệ sông thêm không bệnh sau 5 năm là $53,6 \%$ với thời gian sống thêm khống bệnh trung bình là $63,95 \pm 2,34$ tháng, tỳ

\footnotetext{
${ }^{1}$ Trường Đại học Y Hà Nội

²Bênh viên $K$

Chịu trách nhiệm chính: Nguyễn Thị Trang

Email: drtrang1989@gmail.com

Ngày nhận bài: 3.8.2021

Ngày phản biện khoa học: 5.10 .2021

Ngày duyệt bài: 15.10 .2021
}

Nguyễn Thị Trang ${ }^{1}$, Phạm Hồng Khoa ${ }^{2}$

lệ sống thêm toàn bộ sau 5 năm là $89,2 \%$ với thời gian sống thêm toàn bộ trung bình là $78,70 \pm 1,60$ tháng. Các yếu tố ảnh hưởng đến điều trị bao gồm giai đoạn bệnh, tình trạng thụ thể nội tiết, tình trang HER2. Kết luận: Áp dụng phác đồ 4AC-4D trên bệnh nhân ung thư vú bổ trợgiai đoạn II-IIIA tại bệnh viện Ung bướu Thanh Hóa có hiệu quả cao. bổ trợ.

Tư khóa: ung thư vú giai đoạn II-IIIA, 4AC-4D,

\section{SUMMARY \\ TREATMENT OUTCOME IN PATIENTS WITH STAGE II-IIIA BREAST CANCER TREATED \\ WITH ADJUVANT CHEMOTHERAPY IN \\ THANH HOA ONCOLOGY HOSPITAL}

Objectives: To evaluate survival outcomes and some related factors in patients with stage II-IIIA breast cancer treated with 4AC-4D (A: doxorubicine, C: cyclophosphamide and D: docetaxel) adjuvant chemotherapy. Subjects and methods: Including 74 patients diagnosed with breast cancer stage II-IIIA who underwent radical surgery, adjuvant chemotherapy at Thanh Hoa Oncology Hospital, from February 2014 to April 2021. Results: The mean age of the study group was $46.62 \pm 7.05$ years. All 74 patients completed 8 cycles of 4AC-4D chemotherapy, 